\title{
The novel use of a biliary stent as a temporizing measure in the treatment of severe refractory esophageal stricture
}
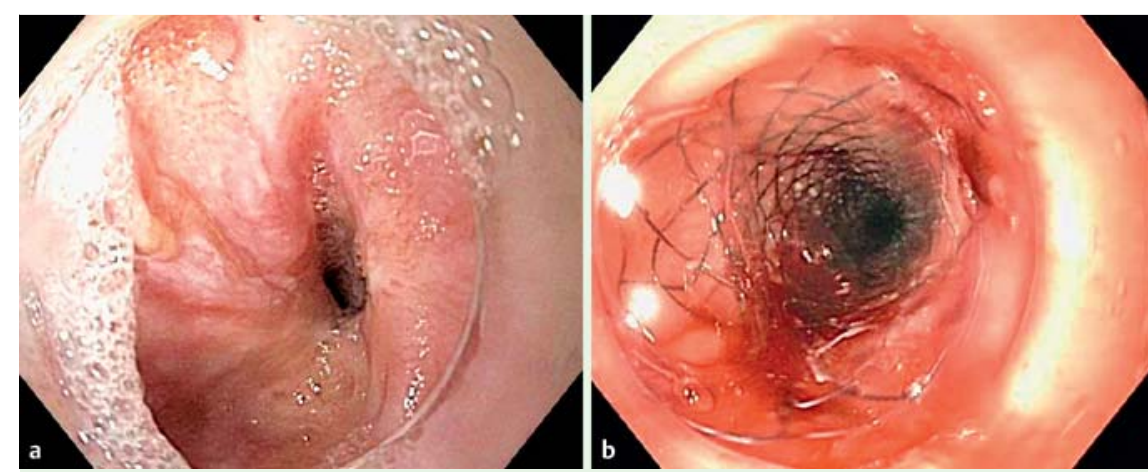

Fig. 1 Endoscopic views showing an intrinsic proximal esophageal stricture: a prior to intervention; b with a biliary stent successfully deployed within it.

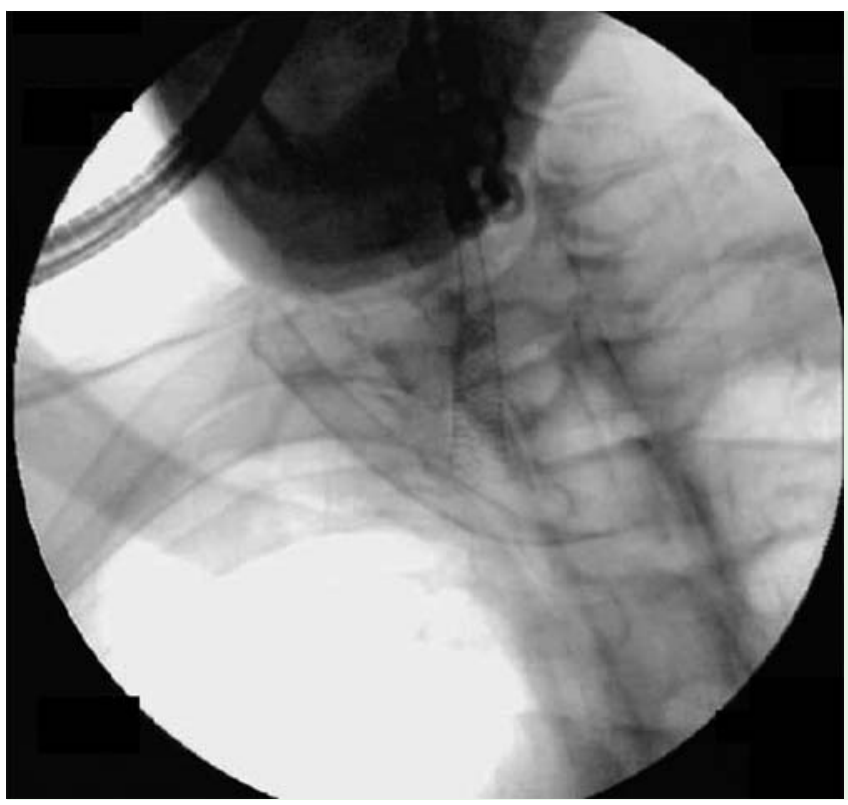

Fig. 2 Fluoroscopic view of the biliary stent deployed within the esophageal stricture.

Esophageal stricture is a narrowing of the esophageal lumen that may result from the use of external beam radiation therapy (EBRT) for the treatment of certain malignancies [1]. Endoscopic dilation is the standard of care; however, stenting is occasionally required. Most manufacturers make esophageal stents with a minimum outer diameter of $16 \mathrm{~mm}$ and few are available in smaller sizes [2]. Occasionally, strictures are so severe that the smallest esophageal stent that is commercially available is too large. An alternative method that has been reported is the off- label use of smaller biliary stents to treat proximal esophageal strictures [3].

A 57-year-old man had a history of laryngeal squamous cell carcinoma (SCC) treated in part by EBRT. This was complicated by the development of a severe post-radiation stricture that persisted despite multiple endoscopic dilations, including those using corticosteroid injection. An upper gastrointestinal endoscopy revealed an intrinsic severe stenosis that could not be traversed ( $\bullet$ Fig. 1 a). A through-the-scope (TTS) dilator was used to dilate the stricture to a balloon size of $10 \mathrm{~mm}$. Placement

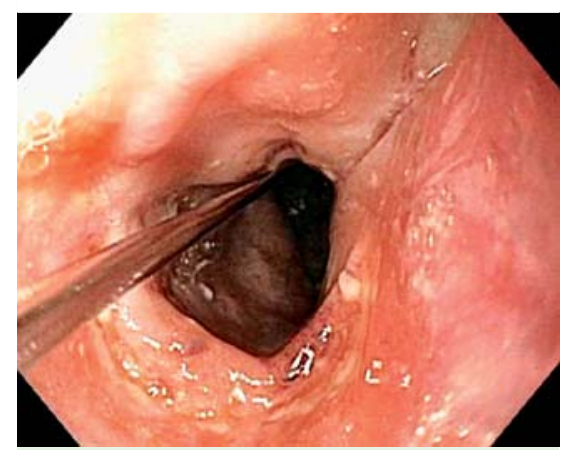

Fig.3 View during repeat endoscopy showing the dilated stricture following removal of the biliary stent.

of a $16 \times 70$-mm ALIMAXX-ES esophageal stent (Merit Medical, South Jordan, Utah, USA) was attempted but was unsuccessful as the stent could not be passed through the stricture. A $10 \times 80-\mathrm{mm}$ fully covered WallFlex biliary stent (Boston Scientific, Marlborough, Massachusetts, USA) was successfully placed under fluoroscopic guidance ( Fig. 1 b and $\bullet$ Fig. 2 ).

A repeat endoscopy 3 weeks later revealed that the previously placed biliary stent remained in the correct position without migration. It was retrieved ( $\bullet$ Fig. 3 ) and a new $14 \times 70$-mm ALIMAXX-ES esophageal stent was successfully deployed for continued dilation.

While more data must be collected to assess the safety, efficacy, and long-term outcomes of this method, the off-label use of fully covered metal biliary stents may be considered in patients with severe refractory esophageal strictures that are otherwise too small for traditional esophageal stents.

Endoscopy_UCTN_Code_TTT_1AO_2AZ

\section{Competing interests: None}

\section{Scott Steinberg, Joshua Anderson, Silvio W. de Melo}

Department of Medicine, Division of Gastroenterology, University of Florida College of Medicine Jacksonville, Florida, USA 


\section{References}

1 Laurell G, Kraepelien T, Mavroidis $P$ et al. Stricture of the proximal esophagus in head and neck carcinoma patients after radiotherapy. Cancer 2003; 97: 1693-1700

2 Hindy P, Hong J, Lam-Tsai Y et al. A comprehensive review of esophageal stents. Gastroenterol Hepatol 2012; 8: 526-534

3 Bechtler M, Wagner F, Fuchs ES et al. Biliary metal stents for proximal esophageal or hypopharyngeal strictures. Surg Endosc 2015; 29: 3205-3208
Bibliography

DOI http://dx.doi.org/

10.1055/s-0042-120711

Endoscopy 2016; 48: E392-E393

(c) Georg Thieme Verlag KG

Stuttgart · New York

ISSN 0013-726X

\section{Corresponding author}

Silvio W. de Melo, Jr., MD

University of Florida in Jacksonville 4555 Emerson Street, Suite 300

Jacksonville

FL 32207

USA

Fax: 1-904-633-0028

Silvio.demelo@jax.ufl.edu 